\title{
Impact of welding the dental enamel walls of the fissure system using semiconductor laser: In-Vitro study
}

\section{Nermin $\mathbf{M Y}^{1^{*}}$, Ali MS ${ }^{2}$ and Samah $\mathbf{S M}^{3}$}

${ }^{1}$ Dental Laser Applications, October University of Modern Sciences and Arts (MSA), Egypt

${ }^{2}$ Medical Laser Applications Department, National Institute of Laser Enhanced Sciences, Cairo University, Egypt

${ }^{3}$ Oral Biology Department, Faculty of Dentistry, Cairo University, Egypt

"Corresponding author: Nermin M Yussif, MSC, periodontology department, October University of modern sciences and arts (MSA) Giza, Egypt, Tel: +20238371517; E-mail: dr_nermin_yusuf@yahoo.com

Received date: July 10, 2017; Accepted date: August 11, 2017; Published date: August 17, 2017

Copyright: (C) 2017 Yussif MN, et al. This is an open-access article distributed under the terms of the Creative Commons Attribution License, which permits unrestricted use, distribution, and reproduction in any medium, provided the original author and source are credited.

\begin{abstract}
Background: Dental caries is as yet considered the commonest disease of childhood and adolescence with high incidence in some individuals. A basic and noninvasive caries preventive regimen as treating tooth enamel with a laser, either alone or in combination have been proved its effectiveness to reduce enamel solubility and caries incidence rates.
\end{abstract}

Methods: Forty specimens were divided into 4 groups, each group contained 10 teeth; group1 (control group) normal enamel; group 2: immersed in artificial caries media; group 3: subjected to diode laser irradiation; group 4: subjected to diode laser irradiation and artificial caries media. Specimens were examined with environmental scanning electron microscope and microhardness measurement.

Results: The environmental scanning electron microscope examination of group 3 revealed partial closure of the occlusal depressions (pits and fissures), and furthermore great resistance to caries occurrence was accomplished in group 4. A high significant difference was recognized in group 3 while group 4 showed non-significant reduction in its hardness.

Conclusions: It was presumed that, diode laser can actuate numerous morphological modifications of the enamel pit and fissure regions as partial to complete closure, increasing the physical, mechanical properties and increasing caries resistance.

Keywords: Microhardness; Diode laser; Fissure system; ESEM

\section{Introduction}

In spite of the fact that a declining rate of dental caries worldwide has been noticed, it is as yet the most pervasive disease affecting youth and adolescence [1]. Several methods of avoidance have been attempted to decrease caries prevalence [2], for example, fluoride application, sealants, preventive resin restorations, and antibacterial therapy, which can be applied to switch the caries process [3]. Nowadays, sealing materials are achieving wide acceptance in the scientific community, however regardless they exhibit few hindrances: contamination of the operation field and contraction during polymerization. These issues have driven specialists to examine alternative solutions keeping in mind the end goal to overcome such limitations [4].

Wear and marginal loss are as yet the most prominent drawbacks of the conventional sealing materials, which prompt exposure of the previously sealed areas [5]. Thus, failure to accomplish a satisfactory bond for fissure sealants might be because of the absence of tag formation following poor etching of the prismless structure lines the fissure system [6].
Attributable to these disadvantages of pit and fissure sealants, consideration was coordinated to laser and its positive outcome on the dental enamel surface. An extensive variety of lasers (as Argon, $\mathrm{CO}_{2}$, Nd: YAG and Er: YAG laser) have been utilized as a part of request to build the resistance of tooth structure to caries. It has been exhibited that laser can fundamentally changes the permeability, the crystalline structure, and advancing an increase in the dental enamel resistance to demineralization [7]. The real phenomenon that causes the impact is related to the chemical-physical changes induced on enamel by laser. The irradiated enamel surface is subjected to water loss between 80 and $1200 \mathrm{C}$, to decomposition of the small quantity of organic substance at $3500 \mathrm{C}$, to initial loss of carbonate hydroxyapatite between $400-6000 \mathrm{C}$, and to enamel melting at more than 800-10000 C.The high temperatures reached in the superficial layers of the irradiated areas of the tooth cause melting of the enamel, which at that point recrystalizes forming hydroxapatite crystals larger than the initial ones [8].

Tagomori et al. [9] found that the irradiated enamel surfaces dependably show higher surface roughness in comparison with the untreated ones. Also, Marquez et al. noticed that the lased surface usually displays 3 layers: un-changed enamel crystals in the internal side of the tooth, fused crystals in the intermediate area and hexagonal hydroxyapatite columns, isolated by voids and micro cracks in the outer surface [10]. 
Citation: Nermin MY, Ali MS, Samah SM (2017) Impact of welding the dental enamel walls of the fissure system using semiconductor laser: InVitro study. Dentistry 7: 447. doi:10.4172/2161-1122.1000447

Page 2 of 5

Among the extensive variety of lasers utilized now in dentistry, diode lasers had many interesting characteristics that make them quite popular among dental practitioners. Their high cost effectiveness, little size and simplicity of usage in the clinical practice regarding to fiber delivery are imperative qualities that support their utilization in clinical practice and energize new studies [11]. The previous studies utilizing diode laser reported that the enamel surface of the deciduous teeth showed melting and resolidification, these alterations propose a resistance increase of the dental enamel versus the acids, thus possibly assuming an imperative role in the prevention of dental caries [12]. The point of the current research is to assess and report the microhardness and morphological alterations happening in fissure system of the human dental enamel following diode laser treatment in order to examine its sealing and anti-cariogenic impact.

\section{Material and Methods}

\section{Sample preparation}

Forty extracted disease free, permanent and recently extracted molars and premolars were used in the experiment. Extraction was accomplished for orthodontic treatment. Teeth debridement of residual soft tissue and calculus was done using dental excavator, curette followed by brushing with prophylactic paste. Utilizing diamond low speed disc, teeth were sectioned into two equal halves bucco-lingually which were used in different groups. Specimens were kept in distilled water prior and after examination [13].

\section{Grouping}

The enrolled specimens were divided into 4 groups to receive different sort of treatment in order to investigate its direct effect on the occlusal depressions and fissure system; Gp1: the included specimens did not receive any treatment (negative control); Gp2: the included specimens were immersed in an artificial caries media; Gp3: the included specimens received laser irradiation without previous enamel surface modifications and finally in Gp 4, the samples received laser irradiation prior to its immersion in the artificial caries media.

\section{Enamel surface treatment}

In groups 3 and 4, enamel occlusal depressions were irradiated using diode laser irradiation of $980 \mathrm{~nm}$ wavelength, $2 \mathrm{~W}$ power for 15 seconds, in contact mode (Quanta system, Italy) and optic fiber transmission system.

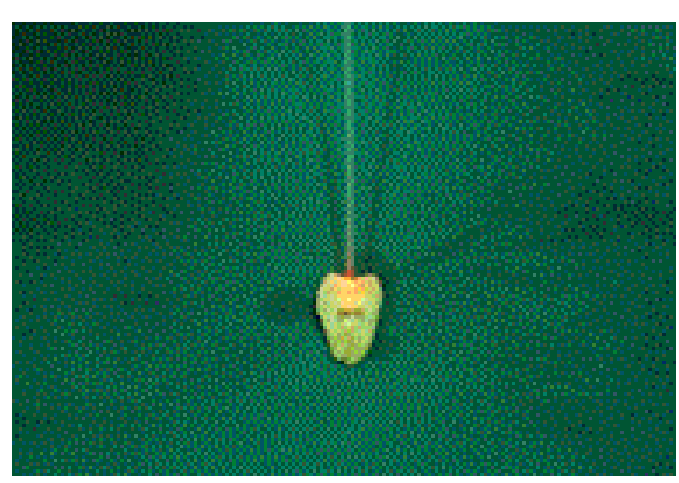

Figure 1: Direction of laser application.

The fiber tip $(320 \mu \mathrm{m})$ was situated perpendicular to the pit and fissure regions (Figure 1). The irradiation process was performed by hand as screening the enamel surface with a uniform movement [14].

\section{Measurements of thermal changes}

Surface and intrapulpal temperature changes were measured using thermocouple analyzer (Fluke 52, USA) in order to assess the progressions during irradiation.

\section{Artificial caries media formation}

Specimens of group 2 and 4 were independently immersed in artificial caries solution (6\% hydroxyethyl cellulose to a $50 \mathrm{~m}$ mole lactic acid solution) with $4.5 \mathrm{pH}$ for 7 days [15]. Specimens were washed and kept in distilled water till usage. In group 2, samples were immersed in the caries media without pre or post treatment modalities in order to investigate the effect of the caries media on the enamel surface in general and the fissure system in specific.

\section{ESEM analysis}

Specimens of each group were examined occlusally and proximally using Environmental Scanning Electron Microscope (Inspect S FEIESEM, Holland). No special preparations were needed prior to microscopic examination. Such property was very useful in examining the specimens before and after in order to guarantee the distinguished outcomes. The occlusal and lateral aspects of the fissure systems were examined in order to detect any changes in the enamel rod orientation, prismatic and interprismatic structure in the presence and absence of fissure sealant material using two different types of microscopical detectors; LFD and BSED.

Only sample pairs of the same tooth were compared and recorded. The use of ESEM has been established for providing a useful means for non-destructive microscopic histomorphography of surface areas of naturally wet oral hard tissues, without the need for a complex preparation and drying process. Another advantage is the avoidance of preparation artifacts.

\section{Microhardness measurements}

Measuring of surface hardness was accomplished using Vickers microhardness tester (HMV-2 Shimadzu, Columbia, US). Measurements were done proximally at the depth of the fissure and at 
the lateral sides of the fissure depth to detect the effect. Indentations were made with the long axis of the knoop diamond perpendicular on the inner enamel surface laterally and at the depth of the fissures. Each group underwent $19.61 \mathrm{~N}$ load applied for $20 \mathrm{sec}$ in order to evaluate the variations of surface hardness, eventually caused by laser treatment in comparison with unlased. The hardness values were calculated automatically by a computerized machine.

\section{Statistical measurements}

The data were gathered and analyzed using ANOVA test. Statistical results were processed by SPSS software (17.0, SPSS Inc., Chicago Ill, USA). Data was subjected to analysis of variance using ANOVA test.

\section{Results}

\section{ESEM analysis}

Total destruction and loss of surface topography were observed clinically in specimens of group 2. Disappearance of the normal elevations and depressions are mainly detected. Structurally, the surface demonstrated a feather-like structure or scaly appearance. Few enamel crystalline aggregations reprecipitated on the decayed surface indicating the demineralization of enamel. Rod and interrod regions were detected at the wall of the fissure due to loss of the surface rodless enamel. The interrod regions appeared as voids that deprived from the normal crystalline arrangement. Contrary to group 2, specimens of group 4 showed a preserved surface structure and morphology of the lased areas. The groove appeared pitted, intact and the nearby enamel showed typical keyhole appearance (rod ends) due to the loss of the rodless enamel. The lateral wall of the pits exhibited an irregular surface due to the presence of areas of melted enamel intermingled with carious enamel. The boundaries between lased and unlased areas were distinct as the intact lased area can be easily distinguished from the surrounded destructed unlased area.

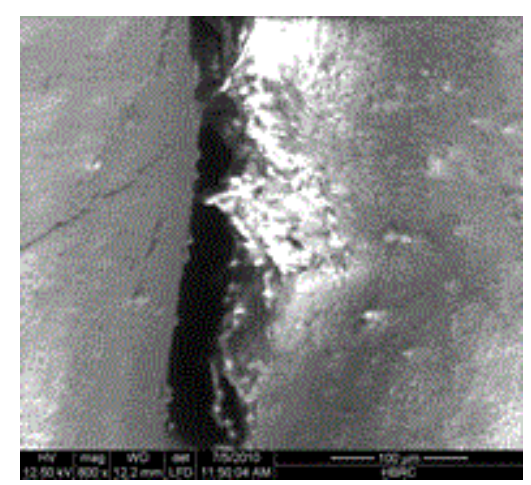

Figure 2: Revealed melting of the enamel of the occlusal fissure with formation of small enamel bridges.

Morphologically in group 3 laser irradiation induced localized enamel fusion of the lateral walls of the fissure providing a sealing like action. Surface pitting was detected occlusally indicating the disappearance of the continuous fissure. The lateral wall of these pits revealed a melted homogeneous enamel surface that was masked by multiple enamel granules. Elimination of the defect was accomplished by the accumulation of some crystals variable in shape and larger size, forming an amorphous and heterogeneous tissue interrupting the prismatic regions. Molten droplets were detected near the irradiated areas. Occasionally; insignificant surface destruction was distinguished (Figure 2).

\section{Measurements of thermal changes}

The measurements recorded only $1^{\circ} \mathrm{C}$ elevation in the intrapulpal temperature and $67^{\circ} \mathrm{C}$ elevation in the surface temperature during lasing. A rapid decay of the gained degrees once lasing has been stopped and returned to the normal temperature in less than 1 minute.

\section{Statistical results}

The statistical analysis of the data was made using ANOVA test. Results were presented as means \pm standard deviations and a p-value less than 0.05 were considered as statistically significant. This analysis detected that both laser treatment and artificial caries treatments had statistically significant effects on the enamel microhardness. So, the degree of demineralization and the ability of each group to resist caries were translated into changes in the microhardness measurements. On comparing all groups with the normal enamel, a highly significant difference was detected ( $\mathrm{p}=0.0001)$. Post Hoc test was done to evaluate the differences among groups as regards the measured normal enamel scores. Group 3 (laser) showed a highly significant difference $(\mathrm{p}=0.0001)$.in most conditions, surface hardness significantly decreased following artificial caries immersion. The contrary was detected in comparing group 4 ( $p>0.05$ ) which revealed main positive effect owing to laser application only.

\section{Conclusion}

Caries is a pathologic dynamic process comprises of various scene successive cycles of demineralization and remineralization [16]. Wave lengths in the red and near infrared regions are ineffectively absorbed by dental minerals however it is ideally transmitted and scattered through sound enamel $[17,18]$. According to literature, no definite explanation was reported to explain beneficial effects of solid state lasers in the previous spectrum such as Nd: YAG laser $(1064 \mathrm{~nm})$ in caries prevention [19]. Because of their low absorption coefficient in hard tissue, neodymium lasers and diode laser $\left(810 \mathrm{~nm}, 100 \mathrm{~mW} / \mathrm{cm}^{2}\right.$, $30 \mathrm{~mW}, 90 \mathrm{sec}$, in a continuous wave) are commonly irradiated with a photosensitizer, which aims to increase the absorption of the laser beam at enamel surface $[20,21]$.

The current study was carried out to investigate the welding like action of diode laser $(980 \mathrm{~nm})$. Surface microhardness was measured in order to detect the changes in the mechanical properties of the enamel surface. Furthermore, identifying the morphological alterations using ESEM analysis was also performed. Due to the non-destruction preparation steps of ESEM, it was recommended to re-examine the same samples following procedure and avoidance of preparation artifacts.

According to the microhardness examination, Statistical significant difference was detected in group 3 (diode laser only) revealed increased surface hardness in comparison to the other groups. On the other hand, group 2 (Artificial caries only) showed the least microhardness results.

Marked morphological changes (group 3, 4) were detected on ESEM examination. Different orientation and shape the enamel prisms, homogenous melting of the enamel rods and loss of the prismatic structure which were in accordance with Mercer et al. [22]. This 
phenomenon was explained by Zuerlein et al. [23] and Fried et al. [24]. Release of the interrod and the intercrystalline substance (mainly water and carbonate) near the lased regions was detected. Regardless the parameters that were used, smooth surface melting and resolidification was established at $1 \mathrm{~W} / 6 \mathrm{sec}[25]$.

On the contrary with Bedini (2010) 25 results using Nd: YAG laser, neglicable microcracks and surface roughness were distinguished with comparable parameters. Fortunately, mimicking the clinical condition by utilizing the free hand technique (continues mode) assisted the reduction of heat accumulation and permit adequate thermal relaxation time [26].

The low absorption coefficient of diode laser (980 $\mathrm{nm}$ wave length) in enamel showed a great benefit as it caused rapid elevation of the surface energy during exposure and rapid decay of temperature once the lasing procedure stopped. It was found that higher temperature than $5.5^{\circ} \mathrm{C}$; irreversible pulp damage could be achieved [27]. In the present study, the difference between the surface and the intrapulpal temperature was only $10 \mathrm{C}$. Furthermore, the elevated surface temperature $\left(67^{\circ} \mathrm{C}\right)$ provides sterilization of the fissure depth as streptococcus bacteria (the causative agent of dental caries) which die at $600 \mathrm{C}$ [28]. So far, no published data are available concerning the effect of $980 \mathrm{~nm}$ high-power diode laser on enamel microhardness [29].

Massive destruction of the enamel surface and the lowest surface hardness was detected in group 2. On the contrary of group 2, the lased samples seemed to keep the normal enamel architecture in spite the fact that the $\mathrm{pH}$ of the used artificial caries media reached below 4.5 as shown in group 4. The appearance of the key holes in group 4 indicated a loss of prismatic structure that was coordinated with the results of Mercer \& Anderson [22]. Group 4 also revealed irregular lateral walls of the pits that might be due to the presence of areas of melted enamel intermingled with carious enamel. Agreeing with our results, Fox et al. [30] showed increase the acid resistance of irradiated enamel proving its potential in preventing caries.

\section{Conclusion}

Although dental enamel is not the chromophore of the diode laser $(980 \mathrm{~nm})$, it was concluded that diode laser can induce sealing like effect (welding) of the enamel fissure system by inducing fusion of the enamel walls. No harmful effect was detected on the dental pulp vitality. Sterilization of the fissure depth, higher acid resistance with better surface hardness was achieved. Caries prevention using diode laser welding mechanism is hardly recommended in teeth with complicated anatomy.

\section{References}

1. Lima YBO, Cury JA (2003) Seasonal variation of fluoride intake by children in a sub topical region. Caries Res 37: 335-338.

2. Ogaard B, Seppa L, Rolla G (1994) Professional topical fluoride applications clinical efficiency and mechanism of action. Adv Dent Res 8: 190-201.

3. Featherstone JDB (2000) Caries detection and prevention with laser energy. Dent Clin North Am 40: 955-969.

4. Ardu S, Perroud R, Krejci I (2006) Extended sealing of interproximal caries lesions. Quintessence Int 37: 423-427.

5. Conry JP, Pintado M, Douglas WH (1990) Measurement of sealant surface area by computer. Quintessence Int 21: 14-17.
6. Burrow MF, Burrow JF, Makinson OF (2001) Pits and fissures etch resistance in prismless enamel walls. Aust Dent J 46: 258-262.

7. Graaff R, Dassel ACM, Koelink MH, Mul FFM, Aarnoudse JG, et al. (1993) Optical properties on human dermis in vitro and in vivo. Appl Opt 32: $435-447$.

8. Rohanizadeh R, LeGeros RZ, Fan D, Jean A, Daculsi G (1999) Ultrastructural properties of laser irradiated and heat treated dentin. J Dent Res 78: 1829-1835.

9. Tagomori S, Iwase T (1995) Ultrastructural change of enamel exposed to a normal pulsed NdYAG laser. Caries Res 29: 513-520.

10. Marquez F, Quintana E, Roca I, Salgado J (1993) Physical-mechanical effects of NdYAG laser on the surface of sound dental enamel. Biomaterials 14: 313-316.

11. Schoop U, Kluger W, Goharkhay K (2006) Innovative wavelengths in endodontic treatment Lasers. Surg Med 38: 624-630.

12. Souza MA, Watanabe I, Azevedo LH, Tanji EY (2009) Morphological alterations of the surfaces of enamel and dentin of deciduous teeth irradiated with NdYAGCO2 and diode lasers. Int J Morphol 27: 441-446.

13. Von fraunhofer JA, Allen DJ (1993) Thermal effects associated with the Nd YAG dental laser. Angle orthod 63: 229-304.

14. Apel C, Meister J, Gotz H, Duschner H, Guttknecht N (2005) Structural changes in human dental enamel after subablative erbium laser irradiation and its potential use for caries prevention. Caries Res 39: 65-70.

15. Issa AI, Preston KP, Preston AJ, Toumba KJ, Duggal MS (2003) A study investigating the formation of artificial caries subsurface enamel like lesions in deciduous and permenant teeth in the presence and absence of fluoride Child. dent health 48: 567-571.

16. Pitts NB (2004)"ICDAS" an international system for caries detection and assessment being developed to facilitate caries epidemiology research and appropriate clinical management. Community Dent Health 21: 193-198.

17. Featherstone JDB, Fried D (2001) Fundamental interaction of lasers with dental hard tissues. Med Laser Appl 6: 181-194.

18. Hennig T, Rechmann P, Jeitner P, Kaufmann R (1993) Caries selective ablation the second threshold. Lasers Ortho Med 1880: 117-124.

19. Ana PA, Bachmann L, Zezell DM (2006) Lasers effects on enamel or caries prevention. Laser Phys 16: 865-875.

20. Bahar A, Tagomori S (1994) The effect of normal pulsed Nd-YAG laser irradiation on pits and fissures in human teeth. Caries Res 28: 460-467.

21. De Sant'anna G, Dos Santos E, Silva Soares L, Do Espírito Santo A, Martin A, et al. (2009) Dental Enamel Irradiated with Infrared Diode Laser and Photoabsorbing Cream Part 1-FT-Raman Study. Photomed Laser Surg 27: 449-507.

22. Mercer CE, Anderson P (1996) X-ray micro tomography a novel technique for the quantification of effects in enamel following $\mathrm{CO} 2$ application. Bri Dent J 12: 451-455.

23. Zuerlein MJ, Fried D, Feather JDB (1999) Modelling the modification depth of carbon dioxide laser treated dental enamel. Lasers Surg Med 25: 335-347.

24. Fried D, Glena RE, Featherstone JDB, Seka W (1997) Permanent and transient changes in the reflectance of $\mathrm{CO} 2$ laser irradiated dental hard tissues at WL9396 103 and $106 \mu \mathrm{m}$ and fluencies of 1-20 J/cm2. Lasers Surg Med 20: 22-31.

25. Bedini R, Manzon L, Fratto G, Pecci R (2010) Microhardness and morphological changes induced by NdYAG laser on dental enamel an in vitro study. Ann Ist Super Sanita 46: 168-172.

26. Apel C, Meister J, Gotz H, Duschner H, Guttknecht N (2005) Structural changes in human dental enamel after subablative erbium laser irradiation and its potential use for caries prevention. Caries Res 39: 65-70.

27. Sulieman M, Rees JS, Addy M (2006) Surface and pulp chamber temperature rises during tooth bleaching using a diode laser a study in vitro. Br Dent J 200: 631-634.

28. Moritz A, Gutknecht N, Goharkhay K, Schoop U, Wernisch J et al. (1997) In vitro irradiation of infected root canals with a diode laser results of 
Citation: Nermin MY, Ali MS, Samah SM (2017) Impact of welding the dental enamel walls of the fissure system using semiconductor laser: InVitro study. Dentistry 7: 447. doi:10.4172/2161-1122.1000447

Page 5 of 5

microbiologic infrared spectrometric and stain penetration examinations. Quintessence Int 28: 205-209.

29. Balabuc C, Miron M, Demian C, Negrutiu M, Filip L, et al. (2007) Effects of $980 \mathrm{~nm}$ high-power diode laser irradiation on enamel microhardness. TMJ 57: 193-197.
30. Fox JL, Yu D, Otsuka M, Higuchi WI, Wong J, et al. (1992) Combined effects of laser irradiation and chemical inhibitors on the dissolutions of dental enamel. Caries Res 26: 333-339. 